\title{
Effects of strychnine on ECS-induced amnesia in the rat*
}

\author{
RALPH R. MILLER and ALAN D. SPRINGER \\ Brooklyn College of CUNY, Brooklyn, N.Y. 11210
}

Rats that received one-trial passive avoidance training followed $15 \mathrm{sec}$ later by electroconvulsive shock displayed extensive memory deficits on a 24 -h retention test. Intraperitoneal injection of strychnine sulfate at various dosages up to $2.0 \mathrm{mg} / \mathrm{kg}$ body weight $1 \mathrm{~min}$ after ECS failed to attenuate amnesia.

McGaugh (1968a, b) has reported that strychnine sulfate attenuated electroconvulsive shock (ECS) induced amnesia in mice. This effect was obtained provided (1) ECS followed training by at least $18 \mathrm{sec}$ and (2) strychnine injection followed ECS by not more than $3 \mathrm{~h}$. The latter constraint is particularly intriguing in that it generally corresponds to the interval subsequent to ECS necessary for amnesia to develop in mice (Geller \& Jarvik, 1968b; McGaugh \& Landfield, 1970). This suggests that strychnine prevents the onset of amnesia rather than facilitates the recovery of unavailable memories. Unfortunately, McGaugh's findings have appeared only in summary format in review articles. Moreover, they are somewhat less than compelling due to arbitrary criterion values defining memory and relatively small intergroup differences reported. The present study examines the effect of strychnine upon ECS-induced amnesia using a paradigm similar to McGaugh's; however, rats rather than mice were used.

As the intention was to prevent amnesia with strychnine, parameters were consistently chosen to maximize any such effect. While amnesia develops in mice over several hours, there is evidence that it may well develop in rats over a period of 15-30 min (Miller \& Springer, 1971). Moreover, McGaugh's data with mice suggest that the shorter the ECS-strychnine interval, the greater the attenuation of amnesia. Therefore, a 1-min ECS-strychnine interval was selected as the minimum convenient interval.

As the degree of amnesia is known to be inversely related to the training-ECS interval, a training-ECS interval was sought that would yield sufficient amnesia to permit an observable reduction through the action of strychnine. However, too short an interval might well create a sufficiently profound effect on

*Supported by USPHS Research Grant MH 19497 and Research Foundation of CUNY Grant 1385. memory such that no amount of strychnine could arrest the onset of amnesia. Pilot studies using a single passive avoidance training trial found that a 20 -sec training-ECS interval failed to produce appreciable amnesia in over a third of the rats convulsed, while a 15-sec interval produced amnesia in almost every animal. Hence, a 15-sec training-ECS interval was used. This interval is similar to the 18 -sec training-ECS interval used successfully in the McGaugh $(1968 \mathrm{a}, \mathrm{b})$ study with mice.

\section{SUBJECTS}

The Ss were 84 naive male albino rats of the Sprague-Dawley strain, 70-90 days old at the beginning of the experiment. They were housed individually and maintained on ad lib water and $10 \mathrm{~g} / \mathrm{day}$ of Purina powdered rat chow. The food deprivation schedule served to minimize the number of animals crippled by ECS. The housing and maintenance schedule was in force for 10 days prior to the beginning of the experiment. Each animal was assigned randomly to one of seven groups of 12 Ss.

\section{APPARATUS}

The apparatus was modeled after the Jarvik \& Kopp (1967) stepthrough device but was modified to accommodate rats rather than mice. The floor of the device was a linear runway $5 \mathrm{~cm}$ wide, composed of two parallel galvanized steel plates, each $2 \mathrm{~cm}$ wide with a $1 \cdot \mathrm{cm}$ gap between them. The metal side walls sloped outward from the floor to a maximum width of $20 \mathrm{~cm}$ at the 28-cm-high Plexiglas ceiling. The device was $60 \mathrm{~cm}$ long and had Plexiglas vertical end walls. A gated partition divided the step-through apparatus into a 16-cm-long white start chamber and a 44 -cm-long black punishment chamber. A $4.5-\mathrm{cm}$ hurdle at the gate was used to augment the distinctiveness of the step-through response. The only illumination in the apparatus was a $25-\mathrm{W}$ incandescent bulb behind the end of the start compartment, $20 \mathrm{~cm}$ above the compartment floor. This served as a mildly aversive stimulus which insured a rather low operant step-through latency.

The two floor plates of the black compartment were connected to a Lafayet te Model A615A constant-current footshock (FS) source calibrated to deliver $2.0 \mathrm{~mA}$ at $60 \mathrm{~Hz}$ for $10 \mathrm{sec}$. These parameters are higher than those normally used in grid floor devices. However, pilot studies showed that the parallel plates of the step-through apparatus necessitated the use of these parameters in order to produce clear-cut one-trial acquisition in virtually all animals receiving FS-only treatment. Any possible bias introduced by these parameters would be evident as a lack of amnesia following FS + ECS treatment; this proved not to be the case.

The partition and roof of the step-through apparatus were slit in order to permit ECS delivery wires connected to earclip electrodes to follow the $S$. The ECS wires were suspended from an overhead pulley and were counterweighted to minimize their effect upon the motion of the animal. ECS was provided by a Lafayette A615B constant-current shock source calibrated to deliver $54 \mathrm{~mA}$ at $60 \mathrm{~Hz}$ for $0.3 \mathrm{sec}$. FS and ECS current parameters were monitored continually during the experiment, using an oscilloscope that was connected across a 10-ohm precision resistor in series with the animal.

\section{PROCEDURE}

The experiment was performed in two replications, with half the Ss from each group within a replication. Initially each animal had earclips affixed and was then placed in the start compartment facing away from the gate. Three seconds later the gate was opened and the S's step-through latency was observed. The criterion for stepping through was four paws on the floor of the black compartment. Upon stepping through, the gate was closed and FS was delivered to the animal. Group FS+IECS+SAL received ECS immediately upon FS offset, followed $1 \mathrm{~min}$ later by a $2.0-\mathrm{cc} / \mathrm{kg}$ body weight IP injection of saline. After a 15-sec delay following FS offset, Group FS+DPECS received pseudo-ECS and G r o p s F $\mathbf{S}+\mathrm{DEC} \mathbf{S}+\mathbf{O}$, $\mathrm{FS}+\mathrm{DECS}+.25 \mathrm{~S}, \quad \mathrm{FS}+\mathrm{DECS}+.5 \mathrm{~S}$, FS+DECS+1.0S, and FS+DECS+2.0S received ECS followed, respectively, $1 \mathrm{~min}$ later by a $0-, .25-, .50-1.0-$, or $2.0-\mathrm{mg} / \mathrm{kg}$ body weight IP injection of strychnine sulfate. Each dosage was prepared to correspond to an injected volume of $2.0 \mathrm{cc} / \mathrm{kg}$ body weight. Following treatment all animals were returned to the home cages.

Twenty-four hours later, exactly following the procedure of the 


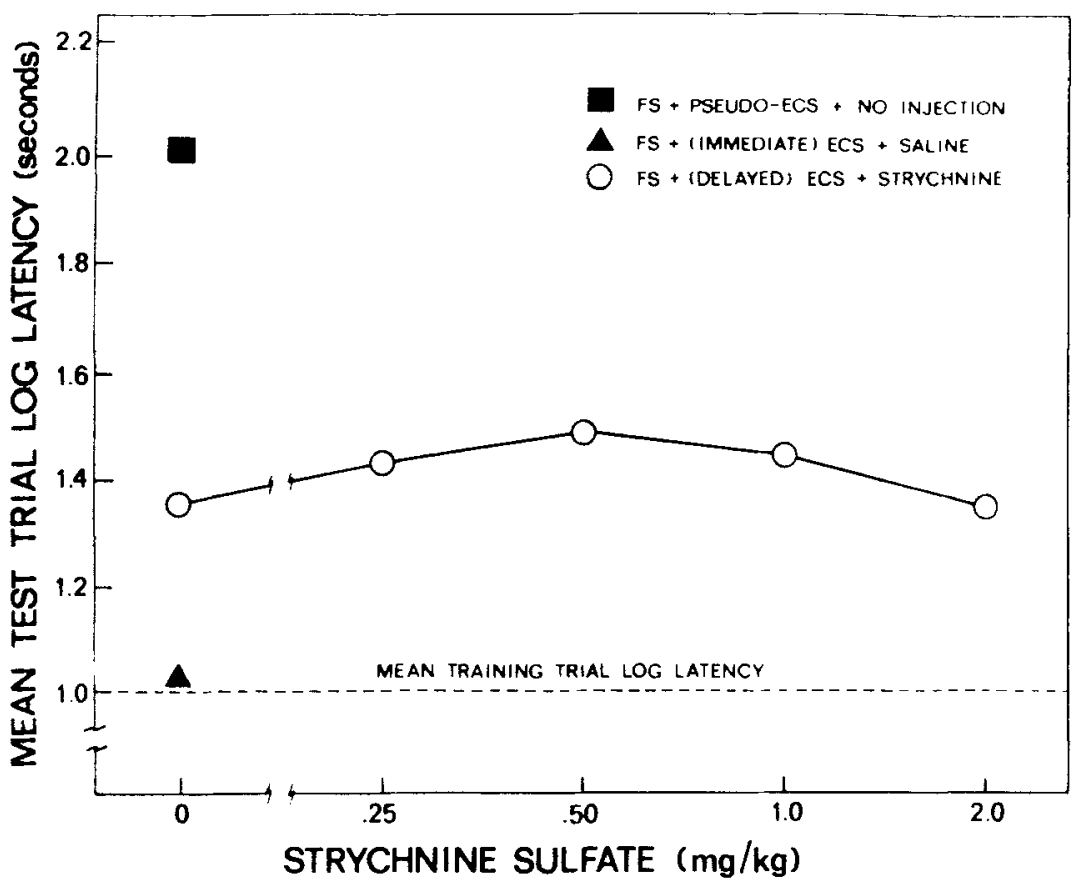

Fig. 1. Mean test trial $\log$ latency in $\log$ seconds as a function of ECS and strychnine sulfate treatment. Delayed ECS was delivered $15 \mathrm{sec}$ after FS off set. Strychnine was injected 1 min after ECS.

previous day, each $\mathbf{S}$ was returned to the start compartment and its step-through latency was observed. A $300-\mathrm{sec}$ cutoff criterion was in force during these test trials. All latencies were transformed to $\log$ latencies to permit a parametric statistical analysis. RESULTS

One-way analysis of variance found no differences in the mean training trial scores of the various treatment groups $[F(6,77)=.94, p>.25]$. Analysis of test trial scores (see Fig. 1) yielded neither replication $[F(1,70)=.35$, $\mathrm{p}>.50]$ nor Treatment by Replication effects $[F(6,70)=.61, \quad p>.50]$ however, the treatment effect proved significant $[\mathrm{F}(6,70)=2.74, \mathrm{p}<.025]$. Individual two-tailed $t$ tests using the common within-group variance from the previous analysis of variance of test scores found Group FS+DPECS to differ from all other groups [5.21 $\geqslant$ $\mathrm{t}(22) \geqslant 3.16$, ps $<.005]$. Group FS+IECS+SAL performed at a level approximately equal to the mean training trial score and fell just short of differing from the strychnine groups $(2.05 \geqslant t \geqslant 1.35, .05<$ ps $<.20)$. The strychnine groups showed no tendency to differ from each other $(.79 \geqslant t \geqslant .07$, ps $>.40$ ).

The effectiveness of the training FS to produce fear is evident in the long test latencies of Group FS+DPECS, and the capability of immediate ECS to produce essentially total amnesia for this training is seen in the very low latencies of Group FS+IECS+SAL.
Moreover, the latter group's behavior indicates that a saline injection $1 \mathrm{~min}$ after ECS does not cause a reduction in ECS-induced amnesia. Group FS+DECS+OS differs from Group FS+IECS+SAL only in that ECS occurred $15 \mathrm{sec}$ later. The higher (but not significantly higher) scores of these animals is consistent with the retrograde nature of ECS-induced amnesia and indicates the "borderline" extent of the amnesia present. Consequently, the strychnine-injected groups would appear to have only a weak amnestic effect to counteract. The highly significant difference between Group FS+DPECS and Group FS+DECS+OS indicates that there is still the potential for a considerable decrement in amnesia due to strychnine treatment.

The almost level dose-response curve for those animals that received strychnine indicates that up to approaches the lethal dose, has had little or no effect upon ECS-induced amnesia. Pilot studies in our laboratory using strychnine dosages of $.2, .4$, and $.7 \mathrm{mg} / \mathrm{kg}$ yielded results entirely consistent with the flat dose-response curve presently obtained. The lack of any appreciable trend in the dose-response curve argues that the inclusion of additional animals over the present number would not alter the outcome. Given the efforts made in the present experiment to obtain a decrement in amnesia via strychnine, the flat $2.0 \mathrm{mg} / \mathrm{kg}$ of this drug, which dose-response curve strongly suggests that post-ECS injection of strychnine does not attenuate amnesia.

It is not clear why McGaugh $(1968 \mathrm{a}, \mathrm{b})$ observed an attenuation in amnesia while we did not, since the task and paradigms were essentially identical in the two studies. Conceivably, the difference in species (mice vs rats) or the disparate mode of ECS delivery (transcorneal vs transpinnate) could account for the apparent discrepancy. Further differences may be recognized when a full report of McGaugh's study is published.

While strychnine failed to prevent amnesia in the present study, this should not be interpreted to mean that there is no post-ECS manipulation that can affect the degree of amnesia. Koppenaal, Jagoda, \& Cruce (1967), Geller \& Jarvik (1968a), Lewis, Misanin, \& Miller (1968), Quartermain, McEwen, \& Azmitia (1970), and Miller \& Springer (1972) have all found that ECS-induced amnesia can be counteracted subsequent to ECS. However, strychnine injected subsequent to ECS apparently is not capable of preventing or reversing amnesia in rats.

\section{REFERENCES}

GELLER, A. \& JARVIK, M. E. Electroconvulsive shock-induced amnesia and recovery. Psychonomic Science, $1968 \mathrm{a}, 10,15-16$.

GELLER, A., \& JARVIK, M. E. The time relations of ECS-induced amnesia. Psychonomic Science, $1968 \mathrm{~b}, 12$, 169-170.

JARVIK, M. E., \& KOPP, R. An improved one-trial passive avoidance learning situation. Psychological Reports, 1967 , 21, 221-224.

KOPPENAAL, R. J., JAGODA, E.. \& CRUCE, j. A. F. Recovery from ECS-produced amnesia following a reminder. Psychonomic Science, 1967, 9, 293-294.

LEWIS, D. J., MISANIN, J. R., \& MILLER, R. R. Recovery of memory following amnesia. Nature, 1968, 220,704-705.

McGAUGH. J. L. A multi-trace view of memory storage processes. Accademia Nazionale dei Lincei, 1968a, 109, 12-24.

McGAUGH, J. L. Drug facilitation of me mory and learning. In D. H. Efron et al (Eds.). Psychopharmacology: A review of progress. Washington. D.C: U.S. Government Printing Office, 1968b, PHS Publ. No. 1836,891-904.

McGAUGH, J. L., \& LANDFIELD, P. W. Delayed development of amnesia following ECS. Physiology \& Behavior, 1970, 5, 1109-1113.

MILLER, R. R., \& SPRINGER, A. D. Temporal course of amnesia in rats after electroconvulsive shock. Physiology \& Behavior, 1971a, 6, 229-233.

MILLER, R. R., \& SPRINGER, A. D. Induced recovery of memory in rats following ECS. Physiology \& Behavior, 1972 , in press.

QUARTERMAIN, D., McEWEN, B. S., \& AZMI TIA, E. C.. JR. Amnesia produced by electroconvulsive shock or cycloheximide: Conditions for recovery. Science, $1970,169,683-686$. 